\title{
De waarde en de rechter
}

\section{Waarom deze beschouwing?}

In het Nivra-verenigingsjaar 1980/1981 is, niet geheel onverwacht, het nieuwe jaarrekeningrecht bij herhaling aan de orde geweest. Nivra-geschrift 24 'Van titel 6 naar titel 8 boek 2 BW' is daarvan het tastbaar bewijs. Een drietal door de Vera ${ }^{1}$ georganiseerde studie-conferenties over het onderwerp trok grote belangstelling. Voor de conferentiegangers kan ik natuurlijk niet spreken, maar wat mijzelf betreft aarzel ik geen ogenblik te erkennen dat ik van de discussies het een en ander heb opgestoken. Ik heb, om in de stijl van de collega's te blijven die de in Nivra-geschrift 24 opgenomen samenvatting hebben verzorgd, in de informatietuin menige vrucht geplukt. En ziet, daardoor ben ook ik uit het paradijs verdreven. Aan de dans van de zalige wetgevingsgeesten kwam een abrupt einde; zij mogen von Gluck spreken, dat zij er zonder kleerscheuren vanaf zijn gekomen. Wat was er aan de hand?

Het najaar 1980 was voor de Nederlandse accountants - en voor hen niet alleen - van bijzondere betekenis. Op 8 september van dat jaar werd bij de Tweede Kamer der Staten Generaal ingediend wetsontwerp 16326 tot aanpassing van de wetgeving aan de vierde richtlijn van de Raad van de Europese Gemeenschappen inzake het vennootschapsrecht. Nu weet iedereen die met het verschijnsel jaarrekening enigszins bekend is, dat niet alleen het formele aspect, de rubricering van bestanddelen van vermogen en resultaat van belang is. Wellicht nog meer geldt dat voor de materiële aspecten: hoe moeten de ondernemingsactiviteiten bedrijfseconomisch worden geïnterpreteerd en vooral met welke getallen moeten de vermogensbestanddelen worden aangegeven?

Het wetsontwerp 16326 bevat in afdeling 6 een zevental artikelen, die zich met het laatst bedoelde materiële aspect bezig houden. Voordat daarin bij nota van wijziging verandering werd gebracht, bevatte lid 5 van artikel 384 een zinsnede, waarin de plicht tot herwaardering van het actief tegen actuele waarde was opgenomen. Deze zou alleen dan gelden, wanneer het inzicht dat de jaarrekening ingevolge artikel 362 lid 1 behoort te geven, ondanks aanvullende toelichting, in ernstige mate zou worden geschaad. Natuurlijk hadden de opstellers van het wetsontwerp niet verwacht, dat een dergelijke bepaling zonder slag of stoot het Staatsblad zouden halen hetzelfde geldt trouwens ook voor andere passages in afdeling 6. Dat zij in bepaalde kringen de gemoederen zo zeer in beroering zou brengen, kwam 
toch wel wat onverwacht. Als $\mathrm{ik}$ mij niet vergis, is inmiddels duidelijk geworden, dat de meest fervente tegenstanders hoofdzakelijk in kringen van de Erasmus Universiteit en haar alumni zijn te vinden. Van elders verneemt men soms bijval voor de geciteerde bepaling, meestal hoort men in het geheel niets. Is er dan toch een silent majority voor de in de aangehaalde bepaling verwoorde gedachte?

Ik wil niet schoolmeesterachtig zijn, maar het moet mij toch van het hart, dat de tegenstanders naar mijn oordeel niet steeds de juiste toon hebben getroffen. Tijdens één van de eerste studiebijeenkomsten naar aanleiding van het wetsontwerp werden de opstellers van slinks optreden beschuldigd en onlangs weer werden zij in het openbaar beticht van 'lippendienst aan de derogerende werking van het getrouwe beeld'. ${ }^{2}$ Hoewel ik meen dat vooral het tweede verwijt een excessief beroep doet op het abstractievermogen van de doorsneelezer, staat wel vast, dat beide uitingen bedoeld zijn om de goede trouw van de opstellers van het wetsontwerp in twijfel te trekken. Ik wil over mijzelf niet spreken, maar ik weet zeker dat de goede trouw van de overigen die bij de opstelling van eerst de vierde EG-richtlijn inzake het vennootschapsrecht en later het wetsontwerp zijn betrokken boven elke twijfel is verheven. $Z$ ij spannen zich tot het uiterste in om op het gebied van het jaarrekeningrecht een aanvaardbare, ook logisch houdbare synthese te bereiken van de communautaire rechtsopvattingen en de $\mathrm{Ne}$ derlandse verworvenheden.

Het was met de controverse over de actuele waarde in gedachten, dat ik aanleiding vond het aan het thema actuele waarde gewijde deel van mijn beschouwingen tijdens de Vera-conferentie te besluiten met de opmerking dat ik erop vertrouwde 'genoeg provocerends over de actuele waarde te hebben gezegd'. In ieder geval heb ik daarmee de aandacht getrokken van de redactie van dit maandblad. Zij toonde zich in het bijzonder geïnteresseerd in een tweetal opmerkingen mijnerzijds. Op pag. 72 van Nivra-geschrift 24 blijkt van mijn vrees' 'dat men lange tijd te weinig recht en te veel boekhouden heeft bedreven'. Midden op de volgende bladzijde prijkt de zin: 'Het is nu eenmaal zo, dat sinds het van kracht worden van de wet op de jaarrekening in het begin van de zeventiger jaren, niet langer de bedrijfseconoom maar de rechter het laatste woord in jaarrekeningzaken heeft'. Zou ik naar aanleiding van deze twee passages niet wat meer kunnen zeggen?, zo de redactie. Ik wil thans proberen aan ieder der beide opmerkingen een hoofdstuk te wijden.

\section{Recht of boekhouden}

De zin over recht en boekhouden, waarmee ik in 1980 mijn opmerkingen over de merites van de actuele waarde voor de jaarrekening besloot, was uiteraard niet meer dan een boutade, een wat gechargeerde uitroep, waarmee ik niettemin poogde een essentieel aspect van de toepassing van het jaarrekeningrecht sinds de jaren zeventig in zeer kort bestek samen te vatten.

De zin heeft inmiddels ook de aandacht getrokken van Beckman. Daarom 
maak ik van deze gelegenheid gebruik om een enkel woord te wijden aan de toelaatbaarheid van de toepassing van actuele waarden volgens de vierde EG-richtlijn.

Beckman is van oordeel, dat ik mij met het betoog dat ik met de bedoelde zin afsloot geheel heb los gemaakt van de inhoud van de vierde richtlijn ${ }^{3}$. In dit betoog plaatste ik een vraagteken bij de maatschappelijke aanvaardbaarheid, onder het nog geldende jaarrekeningenrecht, van de op grote schaal toegepaste, dus blijkbaar aanvaarde waardering op historische grondslag. Van zo'n losmaken kan eenvoudigweg geen sprake zijn, want in die jaren was de vierde EG-richtlijn nog geen geldend recht.

Wellicht, dat de schrijver zijn conclusie trok naar aanleiding van niet geciteerde passages uit mijn in Nivra-geschrift 24 opgenomen beschouwingen. Het zou mij niet verbazen, dat het werkelijk doelwit de voorafgaande alinea is geweest, waarin ik mij verstoutte op te merken, dat naar mijn oordeel het wetsontwerp in den gronde waardering tegen actuele waarde primair stelde. Ik ben sedertdien, ondanks de inmiddels juist in het desbetreffende artikel bij nota van wijziging aangebrachte veranderingen, op dit punt nog steeds dezelfde mening toegedaan.

Van strijdigheid tussen het aldus opgevatte wetsontwerp en de vierde EGrichtlijn kan geen sprake zijn. Artikel 33 van de richtlijn opent immers expressis verbis de mogelijkheid voor de lid-staten om - tot aan latere coördinatie, d.w.z. voorlopig voor ten hoogste zeven jaar - aan de onder hun jurisdictie vallende kapitaalvennootschappen toe te staan bepaalde categorieën van activa tegen één van de toegelaten vormen van actuele waarde in hun jaarrekening op te nemen; ja zelfs om hun dit voor te schrijven.

Aan de beperking van de geldigheidsduur van artikel 33 hecht ik niet al te veel betekenis. Wie de voorgeschiedenis kent, weet dat het niet meer is dan een placebo om de Duitse allergie voor actuele waarden te cureren. Het zou mij sterk verbazen als het nog zou gelukken om het artikel weer uit de richtlijn te verwijderen, en dit niet alleen omdat de opvattingen in andere lid-staten langzaam maar zeker gaan in de richting van aanvaarding van de actuele waarde. De rechtsontwikkeling, die de VVD-fractie blijkens het eindverslag ${ }^{4}$ naar aanleiding van wetsontwerp 16326 voor mogelijk houdt, heeft zich in feite reeds in gang gezet. Eliminering van de in artikel 33 neergelegde grondgedachte ligt ook daarom al niet voor de hand, omdat dit naar mijn overtuiging een onmisbare toepassing vormt van artikel 2 lid 5 van de richtlijn in relatie tot artikel 32 . In laatstgenoemd artikel wordt immers zonder enig voorbehoud de toepassing van aanschaffings- of vervaardigingskosten als leidend beginsel ten troon verheven. Terzelfder tijd echter zaagt artikel 2 lid 5 de poten van deze troon weer door met het sterkere beginsel, dat de jaarrekening steeds een getrouw beeld moet geven van het vermogen, de financiële positie en het resultaat van de vennootschap. Ook de communautaire wetgever heeft deze frictie tussen het alles beheersende getrouwheidsbeginsel en de stellige uitspraak van artikel 32 terdege aangevoeld. Vandaar artikel 33, dat als species van artikel 2 lid 5 uitdrukkelijk aan artikel 32 derogeert. Mocht artikel 33 straks tegen alle verwachting in toch sneven, dan blijft ons altijd nog artikel 2 lid 5.

Ik concludeer dus dat de richtlijn zich niet verzet tegen waardering op 
actuele waarde. Ook niet tegen de verplichte variant, die is gebaseerd op de stelling, dat in bijzondere omstandigheden alleen op actuele basis de getrouwheid is te verwezenlijken, die de richtlijn in artikel 2 lid 3 eist. Een getrouwheid die aanzienlijk meer omvat dan de in het gegeven geval vereiste nauwkeurigheid.

Van deze gedachtengang leverde de bij nota van wijziging geschrapte tweede volzin van artikel 384 lid 5 de Nederlandse vertaling. In de zin werd nadrukkelijk gerefereerd aan het verantwoord oordeel omtrent vermogen en resultaat (artikel 362 lid 1), waartoe de jaarrekening in staat moet stellen. De vervangende tekst van artikel 384 lid 1, die niet is geconcipiëerd met de bedoeling om wijziging te brengen in de anvankelijk beoogde rechtstoestand doet dit trouwens nog altijd.

Om een kleine rechtzetting kom ik niet heen. Bij een eerdere gelegenheid ${ }^{5}$ heb ik opgemerkt, dat de tweede volzin van artikel 384 lid 5 lijnrecht tegen artikel 32 van de richtlijn ingaat. Beckman ${ }^{6}$ citeert deze zin met weglating van de woorden 'artikel 32 van' waardoor het lijkt alsof ik van oordeel zou zijn geweest, dat de befaamde zin uit artikel 384 lid 5 in strijd met de richtlijn was. Mijn uiteenzetting van zoëven zal, hoop ik, duidelijk hebben gemaakt dat dit niet mijn mening weergeeft. $\mathrm{Na}$ alles wat zich in de afgelopen periode heeft afgespeeld, betreur ik dat ik mij destijds niet duidelijker heb uitgedrukt. Hieruit moge blijken, hoezeer ik sindsdien een sadder, zij het volgens sommigen toch geen wiser man ben geworden.

Een tweede rechtzetting moet nu maar meteen volgen. Ik moet een opvatting naar het rijk der fabelen verwijzen die ik heb aangetroffen bij Beckman ${ }^{7}$ en onlangs ook in het november 1982 - nummer van de Revue française de comptabilite ${ }^{8}$. Het gaat hier om het gerucht als zou de Nederlandse regeringsdelegatie bij de onderhandelingen over de vierde EG-richtlijn haar aanvaarding van de schema's voor balans en resultatenrekening afhankelijk hebben gesteld van de opneming van artikel 33. Ik ben van deze onderhandelingen van begin tot eind op de hoogte en kan daarom verklaren, dat deze koppeling nimmer heeft plaats gehad of zelfs maar is overwogen. Het misverstand is in de wereld gekomen door een artikel van Van Bruinessen ${ }^{9}$, waarin deze de gang van zaken schildert tijdens het overleg in de groep van deskundigen uit het Europese accountantsberoep, die door de Europese Commissie was uitgenodigd advies uit te brengen voor een toekomstige richtlijn over het jaarrekeningenrecht. De Nederlandse regeringsdelegatie, waarvan Van Bruinessen geen deel heeft uitgemaakt, heeft er geen probleem in gezien om de schema's, als in het kader van het streven naar vergelijkbaarheid onvermijdelijk te aanvaarden en los daarvan geijverd voor de toelating van waardering tegen actuele waarde. Het is zeer wel denkbaar dat de huidige vierde EG-richtlijn er niet zou zijn gekomen als dit laatste tenslotte niet zou zijn gelukt.

De lezer zal zich inmiddels hebben afgevraagd hoe het voorgaande in verband moet worden gebracht met mijn boutade over boekhouden en recht. Ondanks alle schijn van het tegendeel, ben ik nog steeds op koers naar de door de redactie zo zeer begeerde uitleg. Ook daarin speelt, zoals 
hierna zal blijken, de tegenstelling historische prijzen of actuele waarde een belangrijke rol.

Het is nauwelijks te vermijden dat bij het gereedmaken van een bijdrage aan een publikatie als Nivra-geschrift 24 de gebeurtenissen tijdens de studieconferentie zelf mede tot de uiteindelijke vorm bijdragen. Zo ook in dit geval. Vooral tijdens de eerste zitting, die te Amsterdam plaats vond, is door verschillende debaters met klem betoogd, dat de verslaggeving door huishoudingen zou dienen te geschieden in de vorm van stroominformatie. Dit begrip moet niet worden opgevat als informatie omtrent de geld-goederenstroom, noch in de betekenis, die Van Bruinessen daaraan hecht ${ }^{10}$, de informatiestroom door de hiërarchische geledingen binnen een huishouding. Wat de opponenten voor ogen stond was informatie omtrent de geldstroom door de huishouding. Vermoedelijk hebben zij hetzelfde bedoeld als Bindenga ${ }^{11}$, wanneer hij zegt: 'De laatste jaren is er echter een tendens waar te nemen, dat een goed inzicht in de activiteiten slechts wordt bereikt door weergave van geldstromen. Het cruciale probleem van een financiële jaarrekening is ongetwijfeld het uitdrukken van de veranderingen in vermogenscomponenten in een gemeenschappelijke geldeenheid. Wellicht dat daardoor de recente belangstelling voor de weergave van geldstromen te verklaren is.' In een toelichtende noot bij deze passage geeft hij het volgende actuele historisch overzicht:

\section{'I Cash approach}

II Balance sheet approach

III Income statement approach

IV Funds flow approach voor 1880

$1880-1930$

$1930-1980$

$1980-$

De tijdens de studieconferentie met veel verve gebrachte opvatting omtrent stroominformatie was dus bijna een wereldpremière. Dit strekke tot troost aan de opstellers van het wetsontwerp en aan anderen, die daarin niet onmiddellijk het fundamentele gebrek hebben bespeurd. In de geldstroomopvatting wordt de moeilijkheid dat het niet alles geld is wat er stroomt, opgelost door een extreem nominalistische benadering. Zaken en vermogensrechten zijn niet meer dan voorraden geld in vermomming, nl. de hoeveelheden (of de restanten daarvan) aan geld die nodig waren om het goed te verkrijgen. Waarderen is er niet bij, niet naar boven, maar naar ik begrepen heb ook niet naar beneden. Er resteert alleen een toerekeningsprobleem in de vorm van de vaststelling van de hoeveelheid geld die per balansdatum voor een ondeelbaar ogenblik in goederen is bevroren. Ik doe mijn best de geldstroomopvatting nauwkeurig weer te geven, zoals ik deze heb begrepen. Ik geef echter onmiddellijk toe, dat ik naar alle waarschijnlijkheid niet de meest geschikte persoon ben om deze over het voetlicht te brengen.

Het zal wel niemand verbazen dat ik vooralsnog de mening ben toegedaan, dat, welke de merites van de geldstroomopvatting ook mogen zijn, dit niet de invalshoek van de communautaire en de Nederlandse wetgever is geweest. Ik ken geen land of internationale organisatie, waar deze nieuwe theorie opgeld doet. Natuurlijk staat het de voorstanders vrij hun opvattin- 
gen nationaal, maar vooral ook internationaal met kracht te propageren. Best mogelijk dat na verloop van tijd de wereld bijdraait. Dan zal de communautaire wetgever ook overstag moeten en in zijn kielzog Den Haag. Zolang dit nog geen werkelijkheid is, kan wellicht de staat van herkomst en besteding der middelen het leed verzachten. Maar dan wel een zinvolle staat HBM, die uit meer bestaat dan uit verschillen tussen opvolgende balansposities, die elke lezer zelf ook wel kan bepalen.

Het was vooral op grond van deze nieuw verworven kennis dat ik meende mijn kanttekeningen bij de toepassing van de historische grondslag in de jaren zeventig - een grondslag die het waarderingsprobleem ook, zij het dan niet gans, omzeilt - meende te mogen besluiten met het uiten van de vrees dat men lange tijd te weinig recht en te veel boekhouden heeft bedreven.

\section{De rechter en de bedrijfseconoom}

Zoals ik al heb laten blijken, heeft ook mijn uitspraak dat de rechter het laatste woord in jaarrekeningzaken heeft, de aandacht van de redactie getrokken. Of zij er door is verontrust, weet ik niet. Als dit zo is, klinkt de titel boven dit hoofdstuk voor haar misschien als 'Der Tod und das Madchen'. Dit zou jammer zijn, want er is in het geheel geen aanleiding voor sombere gedachten.

Mijn opmerking had niet de pretentie van bijzondere diepzinnigheid. Ik wilde er alleen nog eens aan herinneren, dat al sinds de invoering van de Wet op de jaarrekening van ondernemingen een gespecialiseerde rechter, de Ondernemingskamer van het Gerechtshof te Amsterdam, bij uitsluiting bevoegd is kennis te nemen van geschillen inzake jaarrekeningen van N.V.'s, B.V.'s, coöperatieve verenigingen en onderlinge waarborgmaatschappijen. Eventueel oordeelt de Hoge Raad nog in cassatie. Ik kan niet aannemen dat ik de lezer hiermee veel nieuws vertel.

Betekent dit dan dat de bedrijfseconomie geen enkele plaats meer heeft in het jaarrekeningenrecht? Niets is minder waar. Natuurlijk is op sommige onderdelen de vrijheid van de verantwoordingsplichtigen om jaarrekeningen op te maken zoals hun dat zint, ingeperkt. Dit gaat echter vooral op voor de meer formele aspecten, zoals de indeling van de jaarrekening. Zelfs dan is er nog sprake van speelruimte. Zo bevat artikel 363 lid 6 in wetsontwerp 16326 in navolging van artikel 4 leden 1 en 2 van de vierde richtlijn, de bepaling, dat bij de toepassing van de schema's voor balans en resultatenrekening indeling, benaming en omschrijving van de daarin voorkomende posten worden aangepast aan de aard van het bedrijf van de rechtspersoon, voor zover dat krachtens de nog vast te stellen algemene maatregel van bestuur zal zijn toegestaan. $\mathrm{Er}$ is geen enkele reden om aan te nemen dat in deze $\mathrm{AMvB}$, in afwijking van de geest van het wetsontwerp zelf, een ijzige verstarrende wind zal waaien. Dit is echter maar een peuleschil vergeleken bij het bedrijfseconomisch gehalte van het leidend beginsel zelf van het jaarrekeningenrecht, dat thans in artikel 362 lid 1 staat: de jaarrekening geeft volgens normen, die in het maatschappelijk verkeer als aanvaardbaar worden beschouwd een zodanig inzicht dat een verantwoord oordeel kan worden gevormd omtrent het vermogen en het resultaat, als- 
mede voor zover de aard van een jaarrekening dat toelaat, omtrent de solvabiliteit en de liquiditeit van de rechtspersoon. Indien de specifieke wetsbepalingen niet ver genoeg gaan, moeten aanvullende inlichtingen worden gegeven. Desnoods moeten zulke bepalingen wijken, indien zij aan de mogelijkheid tot het vormen van een verantwoord oordeel in de weg staan.

Dit zijn de meest wezenlijke bepalingen van het jaarrekeningenrecht. Er is geen enkele aanleiding, ook niet in de inmiddels gevormde jurisprudentie, om, zoals Van Hoepen dat doet, ook maar ergens een element van lippendienst te bespeuren of te construeren. De Nederlandse delegatie heeft tijdens de onderhandelingen over de vierde richtlijn de desbetreffende bepalingen steeds als essentiële elementen daarvan beschouwd. Zouden zij niet zijn opgenomen, dan zou waarschijnlijk door verzet van niet alleen de Nederlandse, maar ook van andere delegaties de richtlijn niet tot stand zijn gekomen. Deze bepalingen en hun Nederlandse tegenhangers tillen de richtlijn resp. de wet uit boven de louter formele sfeer. Alle aspecten van de jaarrekening worden daarmee op flexibele wijze binnen de werkingssfeer van het recht gebracht.

Ik wijs er in dit verband nog op, dat het wetsontwerp zich, behoudens in de zo juist vermelde algemene zin van artikel 362 , hoogst zelden en stellig niet op essentiële onderdelen met de winstbepaling inlaat. Vooral op dit terrein zal een krachtig beroep op de bedrijfseconomie worden gedaan, in het bijzonder wanneer in de jaarrekening actuele waarderingsgrondslagen een rol spelen. Het valt te hopen dat de bedrijfseconomie dan geen verstek zal laten gaan.

Zo moge dan blijken dat in vele en stellig niet de minst belangrijke gevallen, de bedrijfseconoom voorop zal moeten gaan en dat de rechter bij de toepassing van de wet zijn steun niet zal kunnen ontberen, evenmin als in een eerder stadium de verantwoordingsplichtige. De door de redactie ter sprake gebrachte zin had op die situatie betrekking. Zij sloot een wat speculatief betoog af, waarin ik poogde aan te tonen dat zelfs de 'historici' met artikel 384 lid 5 nog wel zouden kunnen leven. Ik ondersteun dan ook Degenkamp ${ }^{12}$, wanneer hij Bindenga's opvatting bestrijdt, dat als gevolg van de wettelijke regeling van de jaarrekeningen een verschraling van het accountantsberoep zal optreden. De grondslagen van verantwoordingen zijn bij uitstek het deskundigheidsterrein van de accountant en juist deze grondslagen zijn maar in zeer algemene bewoordingen in wettelijke regels vastgelegd. Wanneer op dit punt jurisprudentie ontstaat, zal aan de accountant als eerste de taak toevallen de betekenis daarvan voor zijn cliënten te doorgronden. En al moge dan een rechterlijke uitspraak bepalend zijn voor hetgeen vooralsnog geldend recht zal zijn, niets verhindert de accountant om in woord en geschrift van zijn afwijkende opvatting blijk te geven, indien hij van oordeel is, dat in het geldend recht verandering behoort te worden gebracht.

$\mathrm{Al}$ eens eerder ${ }^{13}$ heb ik de parallel getrokken tussen de openbare accountant in de controlerende functie en de rechter oordelend in eerste instantie. Dit is juist de instantie, die ontbreekt in de rechtsgang die de wet voor geschillen over jaarrekeningen in het leven heeft geroepen. De onafhankelijke open- 
bare accountant is geroepen als eerste een oordeel uit te spreken over een door hem gecontroleerde jaarrekening. Met zijn verklaring heft hij de onzekerheid op, die bij belanghebbenden wordt opgeroepen door het feit, dat het bestuur van de rechtspersoon met de jaarrekening over eigen daden verantwoording aflegt. Hij stelt vast wat naar zijn oordeel op het stuk van financiële verantwoording recht is tussen rechtspersoon en belanghebbenden. De wettelijke controleplicht kan worden opgevat als een uitvloeisel van een latent aanwezig conflict tussen deze beide partijen. Natuurlijk weet ik wel dat de vergelijking in vele opzichten mank gaat. Als denkmodel kan zij echter een belangrijk richtsnoer voor het handelen van de openbare accountant opleveren. In elk geval wordt ermee gedemonstreerd hoezeer de ontwikkeling van het jaarrekeningenrecht een nieuw deskundigheidsgebied voor de openbare accountant oplevert.

Met de vrijheidsbeperkende werking van het jaarrekeningenrecht valt het daarom nog wel mee, ook al is de toeneming van aantal en lengte van de wettelijke bepalingen en daarmee van de foutenkans niet onbedenkelijk. Het jaarrekeningenrecht staat hierin helaas niet alleen.

\footnotetext{
Noten

1 Commissie Voortgezette Educatie Registeraccountants.

$2 M$. A. van Hoepen in 'De Accountant', november 1982, pagina's 169 en 170, rechterkolom.

$3 \mathrm{H}$. Beckman: 'Wijzigingen in het jaarrekeningenrecht van de lid-staten van de Europese Gemeenschappen en de vierde EG-richtlijn inzake de jaarrekening', Deventer, 1982, pagina 19. 4 bladzijde 2.

5 'De Naamlooze Vennootschap', september 1980, blz. 159.

6 t.a.p. pag. 18.

7 t.a.p. pag. 21.

8 t.a.p. pag. 471.

9 'De Naamlooze Vennootschap', oktober 1980, pag. 184 sqq.

10 'Handboek accountancy', pag. $1126 \mathrm{sqq}$.

11 A. J. Bindenga: 'De bedrijfseconomische basis van de accountancy', Alphen aan de Rijn, 1981 , pag. 21.

12 zie Nivra-geschrift 28, pag. 14.

13 'De Naamlooze Vennootschap', september 1980, pag. 165.
} 